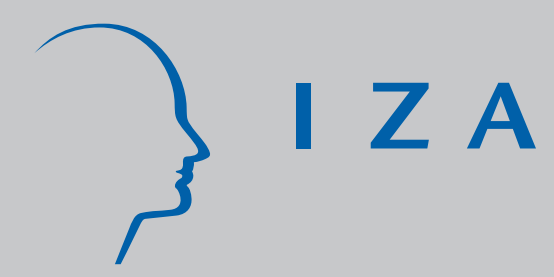

IZA DP No. 1326

Integration, Agglomeration and Welfare

Michael Pflüger

Jens Südekum

October 2004 


\title{
Integration, Agglomeration and Welfare
}

\author{
Michael Pflüger \\ Darmstadt University of Technology, \\ DIW Berlin and IZA Bonn \\ Jens Südekum \\ University of Konstanz
}

Discussion Paper No. 1326

October 2004

\author{
IZA \\ P.O. Box 7240 \\ 53072 Bonn \\ Germany \\ Phone: +49-228-3894-0 \\ Fax: +49-228-3894-180 \\ Email: iza@iza.org
}

Any opinions expressed here are those of the author(s) and not those of the institute. Research disseminated by IZA may include views on policy, but the institute itself takes no institutional policy positions.

The Institute for the Study of Labor (IZA) in Bonn is a local and virtual international research center and a place of communication between science, politics and business. IZA is an independent nonprofit company supported by Deutsche Post World Net. The center is associated with the University of Bonn and offers a stimulating research environment through its research networks, research support, and visitors and doctoral programs. IZA engages in (i) original and internationally competitive research in all fields of labor economics, (ii) development of policy concepts, and (iii) dissemination of research results and concepts to the interested public.

IZA Discussion Papers often represent preliminary work and are circulated to encourage discussion. Citation of such a paper should account for its provisional character. A revised version may be available directly from the author. 


\section{ABSTRACT}

\section{Integration, Agglomeration and Welfare*}

This paper studies the social desirability of agglomeration and the efficiency arguments for policy intervention in a simple, analytically solvable 'new economic geography' model with two trade integrating regions. The location pattern emerging as market equilibrium is "bubbleshaped", i.e. it features dispersion of firms both at high and low trade costs and stable equilibria with partial agglomeration of firms in addition to core-periphery equilibria for intermediate levels of trade costs. Our central finding is that the market equilibrium is characterised by over-agglomeration for high trade costs and under-agglomeration for low trade costs. For very high and very low levels of trade costs as well as for an intermediate range of trade costs, the market equilibrium yields the socially optimal degree of agglomeration. An important implication of this result is that, on efficiency grounds, regional policy should foster the dispersion of firms for a range of high trade costs only, but agglomeration for a range of low trade costs. Hence, regional policies, such as those pursued by the European Union which are aimed at fostering dispersion in general, are counterproductive when trade integration is deep enough.

JEL Classification: F12, F15, F22, R22, R50

Keywords: economic geography, optimal agglomeration, welfare, regional policy

Corresponding author:

Michael Pflüger

Department of Economics

Darmstadt University of Technology

Residenzschloß

64283 Darmstadt

Email: pflueger@vwl.tu-darmstadt.de

\footnotetext{
*We thank Friedrich Breyer, Rainald Borck, Johannes Bröcker, Andreas Haufler, Jochen Michaelis, Horst Raff and participants of the research seminar at the University of Kiel for helpful suggestions and comments and Mariya Bazhlekova for assisting us in performing the computations.
} 


\section{Introduction}

The new economic geography has demonstrated that the interaction among trade costs, increasing returns at the firm level and factor mobility shapes the location of economic activity and can explain the emergence of spatial core-periphery patterns. ${ }^{1}$ Although it derives a good deal of its appeal from its potential to throw light on economic policy (Neary 2001), this research program has been remarkably silent on policy conclusions and on normative issues. However, it is crucial to understand whether the spatial pattern delivered by market forces is also desirable from a social point of view. This issue is far from trivial, since the models of the new economic geography feature several distortions and market failures in parallel. Some of these can be thought of as leading to 'too much' and some to 'too little' agglomeration. Understanding the social desirability of agglomeration from an efficiency perspective is particularly relevant for the design of regional policy, which is an area of toppriority for federal governments and for integrating economies, such as the European Union. Typically, regional policy is not simply intended to redistribute income between rich and poor areas, but rather aims explicitly at a more equal spatial resource allocation. A good example is the European Union, which currently uses roughly one third of its annual budget trying to

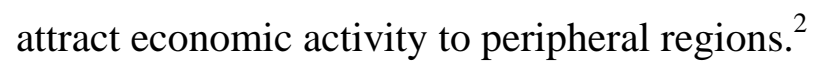

This paper analyses the welfare effects of agglomeration and the efficiency arguments for policy intervention in a specific new economic geography framework which exhibits a particularly plausible pattern of firm location as a process of trade integration unfolds and which allows us to provide all results analytically at the same time. More specifically, we use a footloose entrepreneur model (Forslid and Ottaviano 2003) where the standard CobbDouglas upper tier utility function is replaced by a logarithmic quasi-linear function (Pflüger 2004a). Additionally, we introduce housing costs in the spirit of Helpman (1998) in order to capture (at least) one important congestion force which prevails in practice. The spatial allocation pattern implied by the market is then "bubble-shaped", exhibiting dispersion, agglomeration and redispersion as trade costs between regions are consecutively reduced.

\footnotetext{
${ }^{1}$ The seminal contributions are Krugman (1991), Krugman and Venables (1995) and Venables (1996). For overviews see e.g. Fujita et al. (1999), Fujita and Thisse (1996, 2002), Ottaviano and Puga (1998), Neary (2001) and Ottaviano and Thisse (2003).

${ }^{2}$ See e.g. the Second Cohesion Report of the EU-Commission (2001: 117): “The Treaty [of the European Community], by making explicit the aim of reducing disparities in economic development, implicitly requires that EU policies, and cohesion measures in particular, should influence factor endowment and resource allocation and, in turn, promote economic growth. More specifically, cohesion policies are aimed at increasing investment to achieve higher growth and are not specifically concerned either with expanding consumption directly or with redistribution of income."
} 
Starting at high trade costs and with a dispersion of economic activity, agglomeration is induced by falling trade costs due to supply and demand linkages. At low levels of trade costs, the relative importance of rising housing prices rises and comes to dominate these agglomeration forces so that a redispersion of firms takes place. In contrast to the coreperiphery model of Krugman (1991) and closely related models which feature 'bang-bang' equilibria - either symmetry or full agglomeration in one of two regions -, there are stable equilibria with partial agglomeration in our model. A growing literature shows that equilibria with partial agglomeration are likely to emerge when the standard core-periphery model is modified so as to account for more dispersion forces and/or weaker agglomeration forces. ${ }^{3}$ From the point of view of descriptive realism, frameworks exhibiting such "bubble-shaped" location patterns appear to be favorable to ones implying 'bang-bang' outcomes (Ottaviano and Puga 1998; Puga 2001). Although this view seems to gain ever wider acceptance (Ottaviano and Thisse 2003; Tabuchi and Thisse, 2003; Cavailhès, Gaigné and Thisse, 2004), to the best of our knowledge, our paper is the first to analyse welfare in a model with such realistic features. Moreover, from a purely theoretical point of view, the specific model we set up is the first which formalises the "bubble-shaped" location pattern in an analytically completely tractable manner.

Within this framework we characterise the market location pattern and we derive the spatial allocation chosen by the social planner - which is also "bubble-shaped". Whereas the market allocation is based on the location decision of individual entrepreneurs acting in their own interest, the social planner is assumed to choose the spatial allocation which maximises the sum of utilities of all agents. Crucially, the location decision of mobile entrepreneurs affects the other agents through market-mediated pecuniary externalities which are neglected in the private decision whether to migrate or not. In an otherwise perfect market, these pecuniary externalities would not matter from a welfare point of view since prices then reflect the social values of goods. However, with imperfect competition, these pecuniary externalities matter since changes in prices affect the deadweight loss due to existing distortions (Ottaviano and Thisse 2001, 2002). The social planner internalises these pecuniary externalities. Hence, the market allocation and the social optimum need not coincide. More precisely, we show analytically that the market equilibrium is characterised by over-agglomeration for high trade costs and under-agglomeration for low trade costs. For very high and very low levels and for

\footnotetext{
${ }^{3}$ See Ottaviano and Thisse (2003) for a general assessment and the contributions by Helpman (1998), Tabuchi (1998), Fujita et al. (1999, ch. 14 and ch. 18), Puga (1999), Ludema and Wooton (1999), Forslid and Wooton (2003) and Pflüger (2004a).
} 
an intermediate range of trade costs, the market equilibrium yields the socially optimal degree of agglomeration. On efficiency grounds, policymakers should therefore foster the dispersion of firms for a range of high trade costs only, but agglomeration for a range of low trade costs. Regional policies, such as those pursued by the European Union - which are aimed at fostering dispersion in general -, are counterproductive when trade integration is deep enough. Moreover, putting the welfare of different groups of agents under scrutiny enables us to point precisely to the reasons for the divergence of the optimal spatial structure from the market outcome. It should be noted that these results are derived in a model with specific assumptions about utility and production functions and trade costs. However, this is true for the entire new economic geography literature. Clearly, this specificity commands that we treat the results cautiously. Nonetheless, we believe that our analysis illustrates some fundamental insights for the class of new economic geography models, in general.

Our paper is most closely related to a small set of recent contributions by Helpman (1998), Ottaviano and Thisse (2001, 2002), Ottaviano, Tabuchi and Thisse (2002) and Baldwin et al. (2003: ch. 11) which also analyse the efficiency of the spatial allocation implied by the market equilibrium. These contributions provide the general conclusion that the market equilibrium may not coincide with the social optimum. Being based on different new economic geography models they also provide some more specific conclusions which we discuss and contrast with our results in a later section of this paper, in detail. It should be pointed out at the outset, however, that in contrast to our analysis, neither of these contributions is based on a framework exhibiting an "bubble-shaped" location pattern. Our paper is also more generally related to an evolving literature that evaluates the performance of European regional policy (e.g. Braunerhjelm et al., 2000; Boldrin and Canova, 2001; Midelfart-Knarvik and Overman 2002). Moreover, there is a recent literature which analyses the effectiveness of different policy instruments. These papers show that some policies, e.g. the financing of large-scale interregional traffic networks, may actually be counter-productive in the sense of fostering divergence rather than delivering regional convergence (Martin and Rogers 1995a, 1995b; Martin 1999, 2000; Midelfart-Knarvik 2003; Dupont and Martin, 2004). The more fundamental question of whether there are efficiency reasons for fostering dispersion (or agglomeration) is not addressed in this literature, however.

The structure of our paper is as follows. The next section introduces the model. Section 3 characterises the location pattern emerging as market equilibrium. The socially optimal spatial pattern is derived in section 4. Our central result, the comparison of the allocations of the 
market and the social planner, is presented in section 5. That section also explains in detail how our analysis relates to and deviates from previous work. Section 6 concludes.

\section{The model}

\subsection{The basic set-up}

Our theoretical analysis draws on the two-region quasi-linear 'footloose entrepreneur model' described in Pflüger (2004a) which is a tractable variant of the standard core-periphery model (Krugman 1991; Fujita et al. 1999). ${ }^{4}$ This model is amended to include a non-traded and nonproduced consumption good, housing, in the spirit of Helpman (1998). The economy we consider is composed of two regions, a "domestic" and a "foreign" one, which are assumed to have identical tastes, technologies and (initial) factor supplies. All variables pertaining to the foreign region will be distinguished by an asterisk (*) from domestic variables. There are two types of households, labor households $(L)$ and entrepreneurs $(K)$. They derive utility from an aggregate of manufactures $(X)$ and from an agricultural good $(A)$, both of which are produced and traded, and from housing $(H)$. We assume that an outside country exists whose citizens own the housing stocks of the two regions, $H$ and $H^{*}$, respectively. This assumption serves to neutralise the rental income from housing and keeps the analysis simple. The agricultural good is homogeneous, traded without cost and produced perfectly competitively under constant returns with labor as the only input. This good serves as the numéraire and is assumed to be produced in both regions after trade. The manufacturing aggregate consists of a large variety of differentiated products. Each variety is produced with labor and entrepreneurs. Labor is the only variable input and marginal costs are constant. Entrepreneurs enter only the fixed cost. One entrepreneur is needed to produce at all (e.g. for R\&D or headquarter services). Trade in $X$ is inhibited by iceberg costs. As to the mobility of households, the following is assumed. Labor is intersectorally mobile, but immobile across regions. Entrepreneurs, of which there are $K_{W}$ in the economy overall, are mobile across regions. The share of entrepreneurs who locate in the domestic region is denoted by $\lambda$ and $1-\lambda$ is the share settling in the foreign region. The following description is for the domestic region only. All expressions for the foreign region are analogous.

\footnotetext{
${ }^{4}$ This framework has proven useful in analyses of wage and social policies (Pflüger 2004b) and capital tax competition (Borck and Pflüger 2004). For the terminology "footloose entrepreneur model" and a detailed exhibition of simple agglomeration models see Baldwin et al. (2003) and Ottaviano and Thisse (2003).
} 


\subsection{Preferences and demand}

The two types of households are indexed by $z=L, K$. Each is endowed with and inelastically supplies one unit of their respective productive factor thereby earning wages $(W)$ and entrepreneurial rents $(R)$, respectively. Preferences are homogenous and characterised by:

$$
\begin{aligned}
& U_{z}=\alpha \ln C_{X}+\beta \ln C_{H}+C_{A} C_{X}=\left(\int_{0}^{N} x_{i} \frac{\sigma-1}{\sigma} d i+\int_{N}^{N *} x_{j}^{\frac{\sigma-1}{\sigma}} d j\right)^{\frac{\sigma}{\sigma-1}} \\
& \alpha>0, \quad \beta \geq 0, \quad \sigma>1
\end{aligned}
$$

where $C_{X}$ is the manufacturing aggregate, $C_{H}$ is the demand for housing and $C_{A}$ is the consumption of the agricultural good. Per capita consumption of a domestic (foreign) variety $i$ is denoted by $x_{i}\left(x_{j}\right) . N$ and $N^{*}$ are the number of varieties produced in the home and foreign region, respectively, and $\sigma$ is the elasticity of substitution between manufacturing varieties. The budget constraint of households is given by

$$
P C_{X}+P_{H} C_{H}+C_{A}=Y_{z}, \quad P=\left[\int_{0}^{N} P_{i}^{1-\sigma} d i+\int_{N}^{N^{*}}\left(\tau P_{j}\right)^{1-\sigma} d j\right]^{\frac{1}{1-\sigma}}, \quad \tau>1
$$

where $Y_{z}$ denotes the household's income, $P$ is the perfect CES-price index for the manufacturing aggregate, $P_{i}\left(P_{j}\right)$ is the producer price for domestic (imported) varieties and $P_{H}$ denotes the price of housing. Iceberg transport costs are formalised by the constant parameter $\tau$. These imply that only $1 / \tau$ of a unit of a variety produced in the other region arrives for consumption and that the consumer price of an imported variety is $\tau P_{j}$. Utility maximisation yields the demand functions and indirect utility, $V_{z}:^{5}$

$$
\begin{gathered}
C_{X}=\alpha / P, \quad C_{H}=\beta / P_{H}, \quad C_{A}=Y_{z}-\alpha-\beta, \\
x_{i}=\alpha P_{i}^{-\sigma} P^{\sigma-1}, \quad x_{j}=\alpha\left(\tau P_{j}\right)^{-\sigma} P^{\sigma-1} \\
V_{z}=-\alpha \ln P-\beta \ln P_{H}+Y_{z}+[\alpha(\ln \alpha-1)+\beta(\ln \beta-1)]
\end{gathered}
$$

\footnotetext{
${ }^{5}$ We assume that $\alpha+\beta<Y_{z}$ in order to assure that both types of goods are consumed (cf. Dixit 1990).
} 


\subsection{The housing market}

Equilibrium in the housing market commands that demand, $\beta\left(L+\lambda K_{W}\right) / P_{H}$, be equal to supply of housing, $H$. Hence, equilibrium housing prices are given by:

$$
P_{H}=\beta\left(L+\lambda K_{W}\right) / H
$$

It follows from eq. (5), that the domestic price of housing increases with the share of entrepreneurs, $\lambda$. The converse holds with respect to the other region.

\section{$2.4 \quad$ Production and short-run market equilibrium}

The agricultural good is produced under perfect competition according to the production function $X_{A}=L_{A}$. Since this good is the numéraire, the wage rate is unity, $W=1$.

Each manufacturing variety is supplied by a single firm. Market clearing for a domestic variety $i$ is expressed by $X_{i}=(L+K) x_{i}+\left(L^{*}+K^{*}\right) \tau x_{i}^{*}$, where $X_{i}$ is production and $x_{i}^{*}$ is the demand of the representative foreign household. Part of demand is indirect, caused by transport losses. With $W=1$ and the technology $L_{i}=c X_{i}(c>0$, a constant), the marginal cost is given by $c$. There is a fixed cost, $R$, to compensate the entrepreneur who is needed to produce at all. Profits of the representative domestic firm, $\Pi_{i}$, are then given by:

$$
\Pi_{i}=\left(P_{i}-c\right)(L+K) x_{i}+\left(P_{i}^{*}-c\right)\left(L^{*}+K^{*}\right) \tau x_{i}^{*}-R
$$

Imposing the Chamberlinian large group assumption, each producer perceives an elasticity of demand which is approximately equal to $\sigma$. Hence, profit maximising prices are constant mark-ups on marginal costs:

$$
P_{i}=P_{i}^{*}=c \sigma /(\sigma-1)
$$

The compensation of entrepreneurs adjusts so as to ensure zero profits. Using the market clearing condition, firm scale $X_{i}$ and fixed costs $R$ are related in the following way:

$$
X_{i}=R(\sigma-1) / c .
$$


For a given allocation of entrepreneurs between the two regions, $\lambda$, the nominal returns accruing to entrepreneurs in the two regions, $R$ and $R^{*}$, can be determined by imposing the condition of zero profits on (6) together with the demand functions (3), the price level (2) and firm's optimal prices (7) and the analogue conditions for the foreign region. This gives:

$$
R=\frac{\alpha}{\sigma}\left[\frac{\rho+\lambda}{\lambda+(1-\lambda) \phi}+\frac{\phi(\rho+1-\lambda)}{\phi \lambda+(1-\lambda)}\right] \quad R^{*}=\frac{\alpha}{\sigma}\left[\frac{\phi(\rho+\lambda)}{\lambda+(1-\lambda) \phi}+\frac{\rho+1-\lambda}{\phi \lambda+(1-\lambda)}\right]
$$

where $0 \leq \phi \equiv \tau^{1-\sigma} \leq 1$ is a parameter which captures the freeness of trade and which is inversely related to trade costs. The parameter $\rho \equiv L / K_{W}=L * / K_{W}$ is a measure of the weight of the immobile factor in the two regions and is identical across regions (since $L=L^{*}$ with identical regions). With nominal returns determined by (9), the firm scale $X_{i}$ follows from (8) and the other endogenous variables can be derived in a straightforward way. The $X$ sector employs $N_{C} X_{i}=N R(\sigma-1)$ units of labor which we assume to be less than $L$ in order to ensure that both sectors are active after trade. ${ }^{6}$

\section{Market equilibrium in the long-run}

In the long run, entrepreneurs are assumed to move across regions in response to differences in indirect utilities which they derive in the two locations. The adjustment process over time $t$ is assumed to be governed by the differential equation

$$
d \lambda / d t \equiv \dot{\lambda}=\left(V_{K}-V_{K}^{*}\right) \cdot \lambda \cdot(1-\lambda)
$$

where the utility differential, $V_{K}-V_{K}^{*}=\alpha \ln \left(P^{*} / P\right)+\beta \ln \left(P_{H}^{*} / P_{H}\right)+\left(R-R^{*}\right) \quad$ can be expressed analytically for general trade costs in the following way:

$$
V_{K}-V_{K}^{*}=\frac{\alpha}{1-\sigma} \ln \left[\frac{\lambda \phi+(1-\lambda)}{\lambda+(1-\lambda) \phi}\right]+\beta \ln \left[\frac{\rho+(1-\lambda)}{\rho+\lambda}\right]+\frac{\alpha(1-\phi)}{\sigma}\left[\frac{\rho+\lambda}{\lambda+(1-\lambda) \phi}-\frac{\rho+(1-\lambda)}{\phi \lambda+(1-\lambda)}\right]
$$

The model comprises two agglomerative and two deglomerative forces. Their balance is crucially influenced by the level of trade costs. Hence, although $\lambda=1 / 2$ is always a long-run 
equilibrium (it is easily seen that $V_{K}-V_{K}^{*}=0$ in this case), this equilibrium is not necessarily stable because of the two agglomerative forces. There is a supply linkage as the region with the higher share of entrepreneurs has a larger manufacturing sector and therefore a lower price index. This is captured in the first term in (11). There is also a demand linkage since increasing the share of entrepreneurs in one region implies a larger market. This raises the profitability of firms as expressed by the differential $\left(R-R^{*}\right)$, the third term of (11), and has the effect of attracting further entrepreneurs. A stabilising (deglomerative) effect in the model derives from the fact that, shifting firms from the foreign to the domestic region increases competition among firms for given expenditures on domestic products while lowering competition in the other region, thereby reducing the profitability of the domestic market in relation to the foreign market. This local competition effect can be seen in the third term of (11) holding the denominators constant. In addition to these three forces there is a fourth effect, a deglomerative effect deriving from rising relative housing prices (cf. eq. (5)) which is contained in the second term of (11) and which is independent of trade costs. When trade costs are large, the deglomerative local competition effect prevails and the symmetric equilibrium is stable. However, when trade costs are continuously reduced, the symmetric equilibrium $(\lambda=1 / 2)$ becomes unstable and two stable and increasingly asymmetric equilibria (with $V_{K}-V_{K}^{*}=0$ and $1 / 2<\lambda \leq 1$ or $0 \leq \lambda<1 / 2$ ) emerge in which a larger part, and finally all of the differentiated goods industry is located in one or the other region (i.e. $V_{K}-V_{K}^{*}>0$ and $\lambda=1$ or $V_{K}-V_{K}^{*}<0$ and $\left.\lambda=0\right)$. For still lower trade costs, the deglomerative force of rising housing prices takes over leading to a gradual redispersion of firms until a symmetric equilibrium is reached again. Fig. 1 depicts the utility differential for these five ranges of trade costs and the bifurcation diagram depicted in fig. 2 hence exhibits an "bubble-shaped” pattern.

Fig. 1 and Fig. 2 about here

Due to the simplicity of the model, explicit solutions can be derived for the two levels of trade freeness and the associated level of trade costs at which the bifurcation fork opens and closes. We shall denote the bifurcation point which emerges at low levels of trade freeness the 'market break point', $\phi_{b}^{M}$, and the bifurcation point, where the symmetric equilibrium

\footnotetext{
${ }^{6}$ This implies the parameter restriction $\alpha<\rho \sigma /(2 \rho+1)(\sigma-1)$ as in Pflüger (2004a). This coincidence follows from the fact that no labor input is needed for the housing sector.
} 
becomes stable again, the 'market redispersion point', $\phi_{r}^{M}$. Analytically, these bifurcation levels can be obtained from the condition $\partial\left(V-V^{*}\right) /\left.\partial \lambda\right|_{\lambda=1 / 2}=0$. This yields a quadratic equation which can be solved for the two bifurcation levels

$$
\begin{gathered}
\phi_{b}^{M}=\left(E_{1}-\sqrt{J}\right) / E_{2} \\
\phi_{r}^{M}=\left(E_{1}+\sqrt{J}\right) / E_{2} \\
E_{1} \equiv(\sigma-1)\left[(2 \rho+1)^{2}-\gamma \sigma\right] \quad E_{2} \equiv(\sigma-1)\left[(2 \rho+1)^{2}+\gamma \sigma\right]+(2 \rho+1)(2 \sigma-1) \\
J \equiv(2 \rho+1)^{2}\{1+4 \sigma(\sigma-1)[1-\gamma(\sigma-1)]\}
\end{gathered}
$$

where $\gamma \equiv \beta / \alpha \geq 0$ is a measure for the size of the housing sector relative to the manufacturing sector. In order to obtain two meaningful solutions $0<\phi_{b}^{M}<\phi_{r}^{M}<1$, two assumptions have to be imposed on the parameters of the model. First, in order to obtain a real root in (12) and (13) we require that $J>0$. The parameter restriction $1-\gamma(\sigma-1)>0$ is a sufficient condition to fulfill this requirement. ${ }^{7}$ In economic terms this requires that the degree of increasing returns is strong enough, i.e. $\sigma$ is low enough, in relation to the relative size of the housing sector. ${ }^{8}$ Second, it has to be ruled out that the agglomerative forces become so strong that the symmetric equilibrium is unstable even at infinite trade costs. This 'no black hole-condition' is usually derived be imposing the requirement that the derivative of the utility differential (11) is negative if evaluated at the symmetric equilibrium and for zero trade freeness (i.e. $\left[\partial\left(V-V^{*}\right) /\left.\partial \lambda\right|_{\lambda=1 / 2, \phi=0}<0\right)$. By (11) we can alternatively require that the market break point is strictly positive, i.e. $\phi_{b}^{M}>0$ which commands $E_{1}>\sqrt{J}$. A sufficient condition to fulfill this requirement is given by $\sigma /(\sigma-1)<2 \rho .{ }^{9}$ Economically, this requires that the degree of returns to scale not be too strong (i.e. $\sigma$ not too low) relative to the deglomerative force given by the (relative) stock of immobile workers $(\rho)$. Hence, this condition puts an

\footnotetext{
${ }^{7}$ The necessary condition is weaker, requiring that $1+4 \sigma(\sigma-1)[1-\gamma(\sigma-1)]>0$.

${ }^{8}$ In Dixit-Stiglitz type models, a standard measure of the degree of returns to scale, the ratio of average costs to marginal costs is given by $\sigma /(\sigma-1)$. To see this, note that prices equal average costs in zero profit equilibrium and prices are constant markups on marginal costs according to (7).

${ }^{9}$ Strictly speaking, the inequality $[(\rho / \rho-1)-2 \rho]((2 \rho+1) / \sigma)<\gamma$ has to be satisfied, so that with $\gamma>0$ the no black hole condition is weaker than stated in the body of the text. This is intuitive since an increase in the
} 
upper bound on the agglomerative forces relative to the deglomerative forces of the model, whereas the first condition does just the inverse. One can show that these two conditions and the third parameter restriction which we have imposed to guarantee the activity of the agricultural sector (cf. footnote 6) are mutually consistent. We note in passing that with $\gamma=0$ the bifurcation levels given in (12) and (13) coincide with those in Pflüger (2004a).

The two bifurcation points can be related to the underlying parameters. Straightforward, yet tedious, calculations give:

$$
\begin{array}{lll}
\frac{\partial \phi_{b}^{M}}{\partial \sigma}>0, & \frac{\partial \phi_{b}^{M}}{\partial \rho}>0, & \frac{\partial \phi_{b}^{M}}{\partial \gamma}>0 \\
\frac{\partial \phi_{r}^{M}}{\partial \sigma}<0, & \frac{\partial \phi_{r}^{M}}{\partial \rho}>0, & \frac{\partial \phi_{r}^{M}}{\partial \gamma}<0
\end{array}
$$

Our findings (14) and (15) are summarised in:

Proposition 1: The range of trade costs for which the market does not deliver a stable symmetric equilibrium shrinks with the relative size of the housing sector $(\gamma \equiv \beta / \alpha)$ and rises with the degree of increasing returns at the firm level $(1 / \sigma)$. Increasing the proportion of immobile workers, $\rho \equiv L / K_{W}$, has the effect that both the market break point and the market redispersion point occur at a lower level of trade costs (higher level of trade freeness).

The intuition of these effects is the following. As in the standard core periphery model, increasing the degree of returns to scale at the firm level, $1 / \sigma$, fosters agglomeration. Hence, the market break point occurs at a higher level of trade costs and the market redispersion point at a lower level of trade costs. Increasing the proportion of immobile workers $\rho \equiv L / K_{W}$ bolsters up the dispersion forces at high trade costs which has the effect that it takes lower trade costs to break the symmetric equilibrium. That the market redispersion point obtains at a lower level, too, is most easily understood by thinking of an increase in $\rho$ as due to a fall in the number of entrepreneurs, $K_{W}$, given the number of labour households, $L$. From eq. (5) it can be seen that this lowers the price of housing in the domestic region and thus mitigates the 
deglomerative force of housing prices. Hence, the market redispersion point can only obtain at a lower level of trade costs. The relative size of the housing sector, $\gamma \equiv \beta / \alpha$, acts as a dispersion force. Increasing its size has the effect that both the market break point and the market redispersion point obtain at lower levels of trade costs.

\section{The second-best optimal spatial structure}

\subsection{Welfare}

This section studies welfare. There are two types of inefficiencies in this model. First, firms in the manufacturing sector have market power. Hence, prices exceed marginal costs and the output of firms is too low from a social perspective. Second, a mobile entrepreneur faced with the decision whether to migrate or not, does not take into account the effects of her decision on the welfare of the other agents which are mediated through the profits of firms (rents) and through the price levels in the two regions. As elaborated at length in Ottaviano and Thisse (2001, 2002), these pecuniary externalities, though inconsequential from a welfare point of view in otherwise perfect markets, do matter with imperfect competition.

The distortion arising from the deviation of prices from marginal costs could in principle be addressed by subsidising the output of firms. However, this would necessitate the availability of lump-sum taxes or further inefficiencies arising from distortionary taxation would emerge. ${ }^{10}$ Such lump-sum finance of firm subsidies appears unlikely in practice. Hence, we rule this out in our welfare analysis. Rather, we turn to the question of the second-best optimal spatial structure where the social planner is only able to address the inefficiencies resulting from the location decision of entrepreneurs.

The social planner maximises the joint welfare of the two regions. The social welfare function is the simple utilitarian one, i.e. the sum of the (indirect) utility functions of all agents:

$$
\Omega=K_{W}\left[\lambda V_{K}+(1-\lambda) V_{K}^{*}+\rho\left(V_{L}+V_{L}^{*}\right)\right]
$$

This welfare criterion is reasonable in this model, since all agents' utility functions are quasilinear, and hence all have an identical marginal utility of income equal to one. The social

\footnotetext{
${ }^{10}$ See e.g. Haufler and Pflüger (2003, 2004) for an analysis in the ,footloose capital' version of the monopolistic competition model, i.e. a model which is identical to the one used in this paper except for the fact that the profit accruing the entrepreneurs is repatriated to the country where the entrepreneurs originate.
} 
planner chooses $\lambda$ so as to maximise $\Omega$. It is straightforward to show that the derivative $\partial \Omega / \partial \lambda$ is always equal to zero at $\lambda=1 / 2$. However, it has to be checked whether this is a welfare maximum or a welfare minimum. Moreover, the social welfare function may have further extrema at values different from the symmetric distribution of industries, i.e. at $\lambda \in\{[0,1], \lambda \neq 1 / 2\}$. By standard analysis one can show that the welfare function $\Omega$ has at most five extrema (including the bordercases $\lambda=0$ and $\lambda=1$ ) and that no more than two of these may be welfare maxima. Figure 3 illustrates the possible shapes of $\Omega{ }^{11}$

Fig. 3 about here

The upper graph in fig. 3 illustrates the case where the symmetric equilibrium $(\lambda=1 / 2)$ is a (local and) global welfare maximum. This requires the second derivative of $\Omega$ with respect to $\lambda$ to be negative (i.e. $\partial^{2} \Omega /\left.\partial \lambda^{2}\right|_{\lambda=1 / 2}<0$ ). The bottom of fig. 3 illustrates a case where the symmetric equilibrium is a welfare minimum. In this case, the welfare optimum is a border solution of full agglomeration in one of the two regions (i.e. $\lambda=1$ or $\lambda=0$ ). The panel in the middle illustrates the third possible case. Here, the symmetric equilibrium is a local minimum and the social optima are characterised by partial agglomeration of firms in one region. Both in the second and the third case $\partial^{2} \Omega /\left.\partial \lambda^{2}\right|_{\lambda=1 / 2}>0$. In order to distinguish between these two cases it suffices to evaluate $\partial \Omega /\left.\partial \lambda\right|_{\lambda=1}$. If this derivative is positive, we are in the bottom case of fig. 3 and full agglomeration is optimal from a social point of view. If it is negative, the social optimum is characterised by partial agglomeration (middle panel of fig. 3).

\subsection{The social break point and the social redispersion point}

In the first step we discriminate between the cases where the social planner chooses symmetry and where she chooses (partial or full) agglomeration, leaving the distinction between the cases of partial and full agglomeration to the next section. In accordance with the terminology established in our analysis of market equilibrium, we will speak of a 'social break point' and a 'social redispersion point'. The 'social break point', $\phi_{b}^{s}$, occurs at the (low) level of trade freeness at which symmetry is no longer the social optimum. The 'social redispersion point',

\footnotetext{
${ }^{11}$ In particular one can rule out by contradition that the welfare function has an "W-shape": if it had three welfare maxima (symmetry, $\lambda=1, \lambda=0$ ), three conditions would have to hold: $\partial^{2} \Omega /\left.\partial \lambda^{2}\right|_{\lambda=1 / 2}<0$, $\partial \Omega /\left.\partial \lambda\right|_{\lambda=1}>0$ and $\partial \Omega /\left.\partial \lambda\right|_{\lambda=0}<0$. However, these conditions can be shown to be inconsistent with the parameter restrictions imposed. The cases depicted in fig. 3 are consistent with these restrictions.
} 
$\phi_{r}^{M}$, is the (high) level of trade freeness, at which the symmetric equilibrium re-emerges as the social optimum. We derive these two bifurcation points by taking the second partial derivative of $\Omega$ with respect to $\lambda$ at $\lambda=1 / 2$, setting this expression equal to zero and then solving for $\phi$. Again, this yields a quadratic equation. Provided that the condition $1-\gamma(\sigma-1)>0$ is met $^{12}$, this yields the following two solutions with a real root $\Delta$ :

$$
\begin{gathered}
\phi_{b}^{S}=\left(Z_{1}-\sqrt{\Delta}\right) / Z_{2} \\
\phi_{r}^{S}=\left(Z_{1}+\sqrt{\Delta}\right) / Z_{2} \\
Z_{1} \equiv(2 \rho+1)^{2}-\gamma(\sigma-1), \quad Z_{2} \equiv(2 \rho+1)(2 \rho+3)+\gamma(\sigma-1), \quad \Delta \equiv 4(2 \rho+1)^{2}[1-\gamma(\sigma-1)] .
\end{gathered}
$$

For the case of the social planner a no black hole condition can be derived as well. However, this condition is weaker than the one we have imposed for the market equilibrium. It is easily seen that with $\gamma=0$, the social redispersion (like the market redispersion point) is always equal to one. The comparative statics of these bifurcation levels are as follows:

$$
\begin{array}{lll}
\frac{\partial \phi_{b}^{S}}{\partial \sigma}>0, & \frac{\partial \phi_{b}^{S}}{\partial \rho}>0, & \frac{\partial \phi_{b}^{S}}{\partial \gamma}>0 \\
\frac{\partial \phi_{r}^{S}}{\partial \sigma}<0, & \frac{\partial \phi_{r}^{S}}{\partial \rho}>0, & \frac{\partial \phi_{r}^{S}}{\partial \gamma}<0
\end{array}
$$

These results mimic what we have found for the market equilibrium and the basic intution of the comparative statics carries over. The results are summarised in

Proposition 2: The range of trade costs for which the social planner does not choose symmetry is negatively related to the relative size of the housing sector $(\gamma \equiv \beta / \alpha)$ and increasing with the degree of increasing returns at the firm level $(1 / \sigma)$. Increasing the relative endowment of immobile workers, $\rho \equiv L / K_{W}$, shifts both the social break point and the social redispersion point to lower levels of trade costs.

\footnotetext{
12 This condition has already been imposed as a sufficient condition in our analysis of the market equilibrium.
} 


\subsection{Partial and full agglomeration}

We now turn to the question for what levels of trade freeness the social planner chooses partial agglomeration and full agglomeration, i.e. the distinction between the two cases depicted in the lower panels of fig. 3. These two cases can be distinguished by an inspection of the derivative $\partial \Omega /\left.\partial \lambda\right|_{\lambda=1}$. This expression is given by

$$
\left.\frac{\partial \Omega}{\partial \lambda}\right|_{\lambda=1}=\alpha K_{W}\left\{\gamma \ln \left(\frac{\rho}{1+\rho}\right)-\frac{1}{\sigma-1}\left[\ln \phi+(1-\phi)\left[1+\rho\left(1-\frac{1}{\phi}\right)\right]\right]\right\}
$$

The social planner chooses full agglomeration if this derivative is positive and partial agglomeration if it is negative (cf. section 4.1). To be sure that the bifurcation diagram implied by the social planner's solution is qualitatively the same as the bifurcation diagram of the market equilibrium we provide

Proposition 3: (i) In the vicinity of the social break point and the social redispersion point the social planner chooses partial agglomeration. (ii) There exists a range of levels of trade freeness $\phi$ between the social break point and the social redispersion point where full agglomeration is socially optimal.

The proof of proposition 3 goes as follows. The first part follows from the fact that the derivative of (21) is negative if evaluated at the social break point (i.e. at $\phi=\phi_{b}^{S}$ ). The same holds if this derivative is evaluated at the social redispersion point (i.e. at $\phi=\phi_{r}^{S}$ ). To prove the second part, it suffices to show that there exists an intermediate level of trade freeness, $\hat{\phi}$, in between the two social bifurcation points, $\phi_{b}^{S}<\hat{\phi}<\phi_{r}^{S}$, at which the derivative in (21) is strictly positive. This turns out to be the case, in fact. Hence, on the basis of proposition 3 we can be sure that the bifurcation diagram for the social planner's solution follows qualitatively the same pattern as the bifurcation diagram of the market equilibrium.

\section{$5 \quad$ Market equilibrium and the second best social optimum}

\subsection{The market solution and the second best social optimum compared}

The comparison of the market equilibrium and the social optimum is at the center of our analysis. Subtracting the 'market break point' from the 'social break point' yields: 


$$
\phi_{b}^{S}-\phi_{b}^{M}=\left(\frac{Z_{1}}{Z_{2}}-\frac{E_{1}}{E_{2}}\right)+\frac{\left(Z_{2} \sqrt{J}-E_{2} \sqrt{\Delta}\right)}{Z_{2} E_{2}}>0
$$

as long as $1-\gamma(\sigma-1)>0$, a familiar condition, by now. This result shows, that the social planner switches from a symmetrical equilibrium to partial agglomeration at a higher level of trade freeness (i.e. lower level of trade costs) than the market.

In a similar manner we can compare the 'market redispersion point' and the 'social redispersion point'. This yields:

$$
\phi_{r}^{S}-\phi_{r}^{M}=\frac{Z_{1}+\sqrt{\Delta}}{Z_{2}}-\frac{E_{1}+\sqrt{J}}{E_{2}} \geq 0
$$

as long as $1-\gamma(\sigma-1)>0$ and with strict inequality for $\gamma>0$. This result shows that the 'social redispersion point' emerges at a higher level of trade freeness than the market equilibrium. The central results of our analysis are summarised in

Proposition 4: The market break point is lower than the social break point, and the market re-dispersion point is equal or lower than the social re-dispersion point (strictly lower for $\gamma>0)$.

Proposition 4 implies that the market delivers over-agglomeration for low levels of trade freeness $\phi$ and it delivers under-agglomeration for high levels of trade freeness $\phi$. This result is illustrated in fig. 4 which superimposes the bifurcation diagrams of the market and of the social planner. Solid lines represent the equilibrium spatial structure of the economy and the broken lines the (second-best) optimal spatial structure.

Fig. 4 about here

\subsection{Welfare by group and why the market fails}

In order to dig deeper into the spatial allocation chosen by the social planner and, in particular, in order to gain an intuitive understanding of why the market equilibrium fails to 
provide the optimal spatial configuration for two ranges of trade costs, we perform a welfare analysis for the different groups of factors. This analysis provides

Proposition 5: (i) The group of immobile workers in the two regions prefers dispersion up to a critical level of trade freeness $\phi^{L}$ (characterised below in eq. (25)) and agglomeration at higher levels of trade freeness. (ii) The group of mobile entrepreneurs prefers agglomeration up to the level of trade freeness $\phi^{K}$ (characterised below in eq. (27)) and dispersion for higher levels of trade freeness. (iii) These critical levels can unambiguously be ranked and related to the break and dispersion points of the social planner and the market in the following way: $0<\phi_{b}^{M}<\phi_{b}^{S}<\phi^{L} \leq \phi^{K} \leq \phi_{r}^{M} \leq \phi_{r}^{S} \leq 1$ with strict inequalities for $\gamma>0$.

To prove proposition 5 we proceed in three steps.

(i) The aggregate welfare function of the immobile workers in both regions can be written as

$$
\Omega_{L}=K_{W} \rho\left[V_{L}(\lambda, \phi)+V_{L}^{*}(\lambda, \phi)\right]
$$

Proceeding in a similar manner as in section 4.1, the welfare function $\Omega_{L}$ can be shown always to have an extremum at $\lambda=1 / 2$. In order to find out when this is a welfare maximum rather than a minimum, we analyse the second derivative of the welfare function with respect to $\lambda$ at $\lambda=1 / 2$. This turns out to be a quadratic equation in the level of trade freeness which we equate to zero and solve for $\phi$. Of the two solutions, only one falls in the meaningful range $\phi \in[0,1]$. This critical level which we denote $\phi^{L}$ is given by

$$
\phi^{L}=\frac{(2 \rho+1)[2 \rho+1-2 \sqrt{\gamma(\sigma-1)}-\gamma(\sigma-1)]}{(2 \rho+1)^{2}-\gamma(\sigma-1)}
$$

For $\phi<\phi^{L}, \partial^{2} \Omega_{L} /\left.\partial \lambda^{2}\right|_{\lambda=1 / 2}<0$ and, hence, the symmetrical equilibrium is a welfare maximum. For $\phi>\phi^{L}, \partial^{2} \Omega_{L} /\left.\partial \lambda^{2}\right|_{\lambda=1 / 2}>0$ and symmetry is a welfare minimum for the group of immobile workers as a whole. At $\phi=\phi^{L}$ this group is indifferent as to the spatial allocation of firms. The immobile workers which are equally spread across the two regions prefer dispersion at low levels of trade freeness whilst they prefer agglomeration at high levels of trade freeness. This can be rationalised by observing that there is a conflict of 
interest between the immobile workers in the potential periphery and the potential agglomeration and that, with concave utility, the losses of loosers always outweigh the gains of gainers. ${ }^{13}$ For a given relative size of the housing sector, the disadvantage (advantage) of living in the periphery (the agglomeration) rises with the level of trade costs. Hence, those in the periphery are decisive and it takes a high level of trade freeness to make agglomeration acceptable for them, and in turn, also for the group of immobile workers as a whole. In fact, if there were no housing congestion (i.e. $\gamma=0$ ), the critical level $\phi^{L}$ would rise up to full trade freeness, $\phi^{L}=1$ (see eq. 25). Moreover, the critical level of trade freeness falls with the relative size of the housing sector, $\gamma$, because such an increase reduces the losses of living in the potential periphery.

(ii) Turning to the mobile entrepreneurs, their aggregate welfare function is given by

$$
\Omega_{K}=K_{W}\left[\lambda V_{K}(\lambda, \phi)+(1-\lambda) V_{K}^{*}(\lambda, \phi)\right]
$$

Symmetry $(\lambda=1 / 2)$ is always an extremum of (26), too. From the condition $\partial^{2} \Omega_{K} /\left.\partial \lambda^{2}\right|_{\lambda=1 / 2}=0$ we obtain one critical level $\phi^{K}$ in the range $\phi \in[0,1]$ which reads:

$$
\phi^{K}=\frac{2(2 \rho+1)}{2(2 \rho+1)-\sqrt{(2 \rho+1)^{2}-(4 \rho+1) \gamma(\sigma-1)}}-1
$$

For values $\phi<\phi^{K}, \partial^{2} \Omega_{K} /\left.\partial \lambda^{2}\right|_{\lambda=1 / 2}>0$, and the symmetrical equilibrium is a welfare minimum. For $\phi>\phi^{K}, \partial^{2} \Omega_{K} /\left.\partial \lambda^{2}\right|_{\lambda=1 / 2}<0$, and symmetry is a welfare maximum for the group of mobile entrepreneurs as a whole. Hence, the group of mobile entrepreneurs prefers agglomeration for low levels of trade freeness and dispersion for high levels of trade freeness. Intuitively, the welfare advantage of an agglomeration is smaller, the smaller trade costs. Moreover, without housing scarcity as a centrifugal force, the group mobile entrepreneurs would always favor agglomeration over dispersion (i.e. $\phi^{K}=1$ for $\gamma=0$ ). With an increasing relative size of the housing sector, the critical level $\phi^{K}$ falls below one.

\footnotetext{
${ }^{13}$ The concavity of utility is also critical in the analysis of Ottaviano and Thisse (2002).
} 
(iii) The critical levels $\phi^{L}$ and $\phi^{K}$ can be ranked and related to the break and redispersion points of the market and the social planner. Making use of (17), (18), (22), (23), (25) and (27) it can be derived that

$$
0<\phi_{b}^{M}<\phi_{b}^{S}<\phi^{L} \leq \phi^{K} \leq \phi_{r}^{M} \leq \phi_{r}^{S} \leq 1
$$

with strict inequalities for $\gamma>0$. The ranking provided in (28) gives us insights both about the spatial allocation chosen by the social planner as well as why the market fails for some ranges of trade freeness.

The social planner maximises the joint welfare (i.e. the sum of indirect utilities) of the immobile workers and the mobile entrepreneurs and can thus be seen as balancing their interests and choosing the social break and redispersion points, accordingly. In the range $\phi^{L}<\phi<\phi^{K}$ both the immobile workers and the mobile entrepreneurs prefer agglomeration over dispersion. Hence, the social planer chooses agglomeration in this range as well. However, for levels of trade freeness below $\phi^{L}$, the immobile prefer symmetry whilst the mobile prefer agglomeration. Since the social welfare function attaches weight not only to the immobile but to the mobile as well, the social break point must be below $\phi^{L}$. Inverse reasoning implies that the social redispersion point must be above $\phi^{K}$.

The spatial allocation provided by the market differs from the social planners allocation because it is only the welfare motive of the individual entrepreneurs expressed in (10) which guides the market allocation rather than the welfare of the groups of immobile and mobile factors together. The ranking provided in (28) shows that there are ranges of trade freeness at which there is a harmony of interest between the individual entrepreneurs and the group of immobile workers and there are other ranges where there is a conflict of interest. A similar result, albeit with different ranges of trade freeness, holds with respect to the indivual entrepreneurs and the group of mobile entrepreneurs as a whole.

A different way to rationalise the divergence between the market allocation and the allocation of the social planner is obtained by noting that the first order condition for the social planner can be written as ${ }^{14}$

$$
\Omega / d \lambda=K_{W}\left[\left(V_{K}-V_{K}^{*}\right)+\left(\lambda V_{K}{ }^{\prime}+(1-\lambda) V_{K}^{*}{ }^{\prime}\right)+\rho\left(V_{L}{ }^{\prime}+V_{L}^{*}{ }^{\prime}\right)\right]
$$

\footnotetext{
${ }^{14}$ The following reasoning is similar to the analysis in Ottaviano and Thisse (2002).
} 
The first term in the straight bracket is the utility differential which guides the individual entrepreneurs. The other terms can be interpreted as the net pecuniary externality originating from the location decision of the market on the group of mobile entrepreneurs as a whole (second term) and on the group of immobile workers (third term). As is clear from (28), the sign of the net pecuniary externality both on the other groups individually and on the two groups together depends on the range of trade freeness. It is zero in the range $\phi^{L}<\phi<\phi^{K}$, because in that range there is harmony of interest, i.e. all prefer agglomeration. The net pecuniary externality on the two groups together may be positive and hence the market may provide too little agglomeration; the net pecuniary externality on the two groups may also be negative and hence the market may provide too little agglomeration. This provides an intuitive rationalisation for proposition 4. Moreover, the net pecuniary externality on different groups may differ. Finally, for high levels of trade freeness (levels in the range $\phi^{K}<\phi<\phi_{r}^{M}$ ) the market (the individual entrepreneurs) selects agglomeration whilst the group of mobile entrepreneurs as a whole would prefer dispersion. Intuitively, the individual entrepreneurs do not fully take into account that agglomeration has negative effects due to high housing prices and due to local competition on the group of mobile entrepreneurs as a whole.

\subsection{Discussion}

The main conclusion from our analysis is that the market equilbrium is characterised by overagglomeration for low levels of trade freeness and by under-agglomeration for high levels of trade freeness. Hence, there are two ranges of trade freeness where policy interventions based on efficiency considerations are justified. However, while the optimal policy for low trade freeness is to foster dispersion, the opposite holds true for high levels.

It is worthwhile to put our results in perspective to the previous literature. In common with Helpman (1998) we obtain the result that there is too little agglomeration at high levels of trade freeness. However, whereas Helpman relies on numerical simulations, we are able to provide the redispersion points of the market and the social planner analytically. This is essentially due to two differences. Whereas our analysis is based on a more tractable logarithmic quasi-linear utility function, Helpman uses a Cobb-Douglas function. Moreover, in contrast to the model we use, there is no constant returns sector and there is no immobile labour force in Helpman's model. Intuitively, by eliminating immobile workers as a dispersion force, both the market and the social planner prescribe agglomeration for low enough levels of trade freeness in Helpman's model. There can thus be no divergence 
between the market and the social planner at low levels of trade freeness in his model. Another important difference between our analysis and the analysis of Helpman derives from the fact that with a Cobb-Douglas utility function, the marginal utility of income is not constant and may differ across agents. However, social welfare analysis has a bias toward an equity driven redistribution in this case and such utility frameworks are thus not really suited to address the efficiency question in purity (Baldwin et al. 2003: 252; Ottaviano and Thisse 2002: 432). With a quasi-linear utility function, the marginal utility of income is constant (unity) and efficiency analysis is precise, in contrast.

The work of Ottaviano and Thisse $(2001,2002)$ is based precisely on such a framework. They use the footloose entrepreneur model with a quadratic quasi-linear upper tier utility function set out in Ottaviano, Tabuchi and Thisse (2002). This yields a linear model with two main differences compared to the model we use. Firstly, it does not feature stable locational equilibria with partial agglomeration, but it only allows for 'bang-bang'-outcomes. When deriving their normative conclusions, Ottaviano and Thisse (2002) are thus restricted to a comparison of corner solutions. Secondly, they do not consider a congestion force such as housing and consequently there is no redispersion. In their model there can only be overagglomeration, but never under-agglomeration at low trade costs. A meaningful comparison of their results with our results is obtained when the housing sector is eliminated in our analysis, i.e. by imposing $\gamma=0$. Our framework then also implies that there can only be overagglomeration. Interestingly enough, Ottaviano and Thisse (2002) obtain a different ranking of critical thresholds than (28). In line with our results, the market break point occurs at higher (positive) trade costs than the social break point in their analysis. However, below a critical level of trade costs, the group of mobile entrepreneurs which lies between the market break point and the social break point, the group of mobile entrepreneurs as a whole prefers dispersion, rather than agglomeration. In our model, in contrast, $\phi^{K}=1$ when $\gamma=0$, i.e. the group of mobile entrepreneurs always favors agglomeration when there is no housing sector as congestion force. This difference is due to the local competition effect which acts as a dispersion force and which is stronger with linear demand functions than with iso-elastic demand (our framework) because lower trade-cost inclusive prices imply a higher elasticity of demand and hence a stronger local competition effect. The group of mobile entrepreneurs internalises this local competition effect and, hence, prefers dispersion at positive trade costs in the model of Ottaviano and Thisse (2002). 
In an extension of this framework, Ottaviano, Tabuchi and Thisse (2002) introduce urban commuting costs as a dispersion force. This framework is the one most closely related to the model used in this paper. They even provide a brief analysis of the efficiency of the market outcome which reveals that the market equilibrium may yield either suboptimal agglomeration or suboptimal dispersion. However, compared to our analysis (with $\gamma>0$ ), they do not provide clear-cut analytical thresholds for when either of these two cases obtains, but they supply suggestive simulations, only. Moreover, they do not show that welfare properties of agglomeration change through the different stages of trade integration.

The analysis of Baldwin et al. (2003, Chapt. 11.3) relies on a version of the footloose entrepreneur model where the upper tier utility is Cobb-Douglas rather than of the quasi-linear type and they do not allow for a housing sector or any other congestion force. They show that the market outcome provides excessive agglomeration (agglomeration already at high levels of trade costs where the second-best social planner would still choose dispersion) if agglomeration forces are strong and the size of the immobile labour force is large relative to the size of the group of mobile entrepreneurs. Excessive dispersion occurs if agglomeration forces are weak and the relative size of immobile workers is small. As noted above, the CobbDouglas utility implies an equity bias in the welfare analysis. This may be responsible for why their results diverge from ours and those provided by Ottaviano and Thisse (2001, 2002).

\section{Conclusion}

This paper has addressed the welfare effects of agglomeration and the efficiency arguments for regional policy intervention. Our analysis contrasts and improves on previous work in this area in two main respects. First, it is based on a framework that has the attractive feature that the location pattern implied by the market equilibrium is "bubble-shaped". Previous contributions exhibited 'bang-bang' outcomes only and thus were restricted to a comparison of corner solutions in their normative analysis. Second, our framework remains analytically tractable even though we include housing scarcity as an additional centrifugal force, which implies the realistic feature of redispersion of economic activity at high levels of trade freeness. Thereby we were able to derive a richer menu of normative results as compared to previous work (cf. section 5.3) and to provide a clear-cut picture of the welfare properties of agglomeration as the two-region economy goes through the different stages of the trade integration process. We show that the market equilibrium is characterised by overagglomeration for high trade costs and under-agglomeration for low trade costs. For very high and very low levels of trade costs and for an intermediate range of trade costs, the market 
equilibrium yields the socially optimal degree of agglomeration. Hence, considerable doubt should be cast on the traditional wisdom that regional policies should always foster a dispersion of industries. Rather, from the perspective of allocative efficiency, it turns out that more agglomeration would be socially optimal when trade integration has developed far enough. These results, as all results in the research program of the new economic geography, draw on a specific framework. For this reason, our policy conclusions should be treated with caution. Nonetheless, we believe that our analysis serves to illustrate some fundamental insights that are at work in new economic geography models.

\section{References}

Baldwin, R.E., R. Forslid, P. Martin, G.I.P. Ottaviano and F. Robert-Nicoud, 2003, Economic geography and public policy, Princeton University Press

Boldrin, M. and F. Canova, 2001, Inequality and convergence in Europe's regions: reconsidering European regional policies, Economic Policy, 206 - 253

Borck, R. and M. Pflüger, 2004, Agglomeration and tax competition, IZA-Discussion paper 1033

Braunerhjelm, P, R. Faini,V. Norman, F. Ruane, P. Seabright, 2000, Integration and the regions of Europe: How the right policies can prevent polarization, Monitoring European Integration 10, CEPR 2000

Cavailhès, J., C. Gaigné and J.-F.Thisse, 2004, Trade Costs versus Urban Costs, CEPR Discussion Paper 4440

Dixit, A., 1990, Optimization in economic theory. Second Edition, Oxford University Press.

Dupont, V. and P. Martin 2004, Subsidies to poor regions and inequalities: some unpleasant arithmetic, CEPR Discussion Paper 4107

EU-Commission (2001), Second Report on Economic and Social Cohesion, Brussels, http://europa.eu.int./comm/regional_policy/sources/docoffic/official/reports/ contentpdf_enf.htm

Forslid, R. and Ottaviano, G.I.P., 2003, An analytically solvable core-periphery model. Journal of Economic Geography, 3, 229 - 240.

Forslid, R. and I. Wooton, 2003, Comparative advantage and the location of production, Review of International Economics 11(4), 588-603

Fujita, M., P. Krugman and A.J. Venables, 1999, The spatial economy. Cities, regions, and international trade, MIT-Press, Cambridge, Mass.

Fujita, M. and J. Thisse, 1996, Economics of agglomeration, Journal of the Japanese and International Economies 10, 339-378

Fujita, M. and J. Thisse, 2002, Economics of agglomeration, cities, industrial location, and regional growth, Cambridge University Press

Haufler, A. and M. Pflüger, 2003, Market structure and the taxation of international trade, CESifo-Working paper 1080

Haufler, A. and M. Pflüger, 2004, International commodity taxation under monopolistic competition, Journal of Public Economic Theory 6(3), 445-470

Helpman, E., 1998, The size of regions, In: D. Pines, E. Sadka, I. Zilcha (eds.), Topics in public economics. Theoretical and empirical analysis, Cambridge University Press, 33-54

Krugman. P., 1991, Increasing returns and economic geography, Journal of Political Economy 99, 483-499. 
Krugman, P., and A. J. Venables, 1995, Globalization and the inequality of nations, Quarterly Journal of Economics 60, 857-880.

Ludema, R. D. and I. Wooton, 1999, Regional integration, trade and migration: are demand linkages relevant in Europa? In: R. Faini, J. De Melo and K.F. Zimmermann (eds.), Migration. The controversies and the evidence, CEPR and Cambridge University Press, 51-75

Martin, P., 1998, Can regional policies affect growth and geography in Europe, World Economy, 757-774

Martin, P., 1999, Public policies, regional inequalities and growth, Journal of Public Economics 73, 85-105

Martin, P., 2000, The role of public policy in the process of regional convergence, European Investment Bank Papers 5, 69-79

Martin, P. and C. Rogers, 1995a, Industrial location and public infrastructure, Journal of International Economics 39, 335-351

Martin, P. and C. Rogers, 1995b, Trade effects of regional aid, in: R. Baldwin, P. Haaparanta and J. Kiander (eds.), Expanding membership of the European Union, Cambridge University Press, 166-188.

Midelfart-Knarvik, K.H. (2004), Regional policy desing: an analysis of relocation, efficiency and equity, CEPR Discussion Paper 4321

Midelfart-Knarvik, K.H. and H.G. Overman, 2002, Delocation and European integration: is structural spending justified? Economic Policy, 17(35) 322-359

Neary, P.J., 2001, Of hype and hyperbolas: introducing the new economic geography, Journal of Economic Literature 39, June, 536-561

Ottaviano, G.I.P. and D. Puga, 1998, Agglomeration in the global economy: a survey of the 'new economic geography”, World Economy, 707-731

Ottaviano, G.I.P. and J.-F. Thisse, 2001, On economic geography in economic theory: increasing returns and pecuniary externalities, Journal of Economic Geography 1, 153179

Ottaviano, G.I.P. and J.-F. Thisse, 2002, Integration, agglomeration and the political economics of factor mobility, Journal of Public Economics 83, 429-456

Ottaviano, G.I.P. and J.-F. Thisse, 2003, Agglomeration and economic geography, draft chapter for the Handbook of Regional and Urban Economics: Cities and Geography, ed. by J.-F. Thisse and V. Henderson, November

Ottaviano, G.I.P., T. Tabuchi and J.-F. Thisse, 2002, Agglomeration and trade revisited, International Economic Review 43, 409-435

Pflüger, M., 2004a, A simple, analytically solvable, Chamberlinian agglomeration model, Regional Science and Urban Economics 34, 565-573

Pflüger, M., 2004b, Economic integration, wage policies and social policies, Oxford Economic Papers 56(1), 135 - 150

Puga, D., 1999, The rise and fall of regional inequalities, European Economic Review 43, 303-334

Puga, D., 2001, European regional policies in light of recent location theories, CEPR Discussion paper 2767

Tabuchi, T., 1998, Agglomeration and dispersion: a synthesis of Alonso and Krugman, Journal of Urban Economics 44, 333-351

Tabuchi, T. and J.-F.Thisse, 2003, Regional Specialization, Urban Hierarchy, and Commuting Costs, CORE Discussion Paper No.2003-60

Venables, A.J., 1996, Equilibrium location of vertically linked industries, International Economic Review 37, 341-359. 
Figure 1: Equilibrium geographical structure

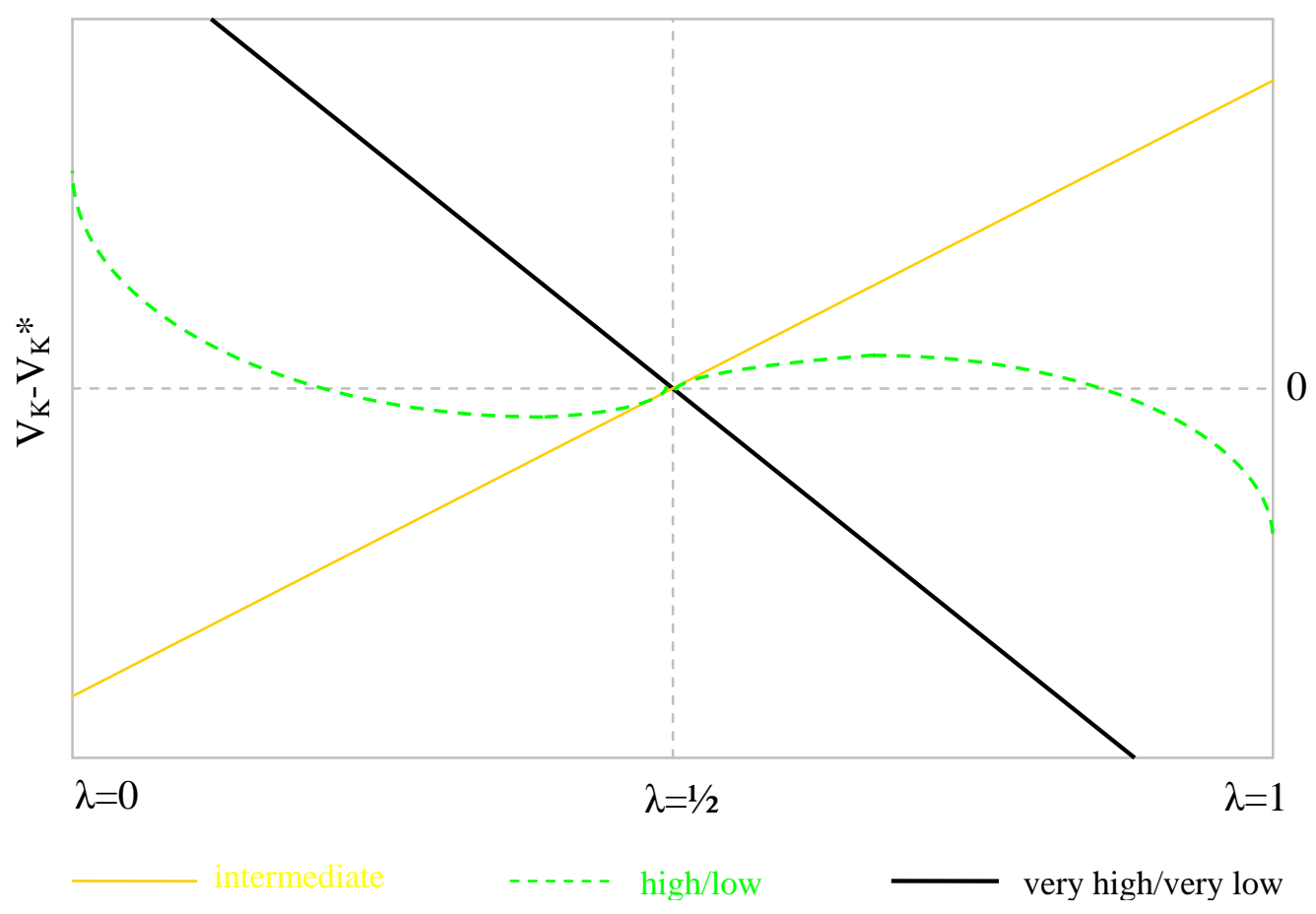

Figure 2: The bifurcation diagram

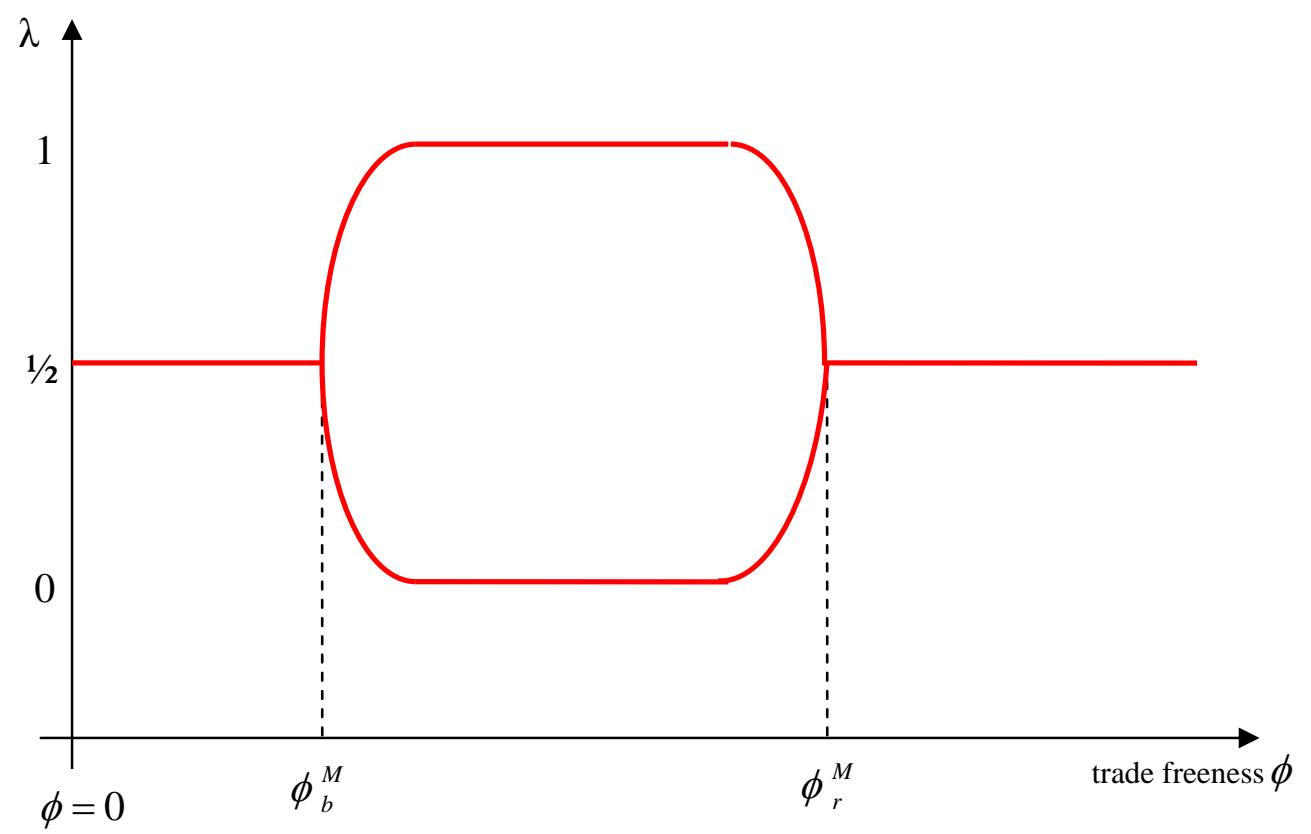


Figure 3: Social welfare

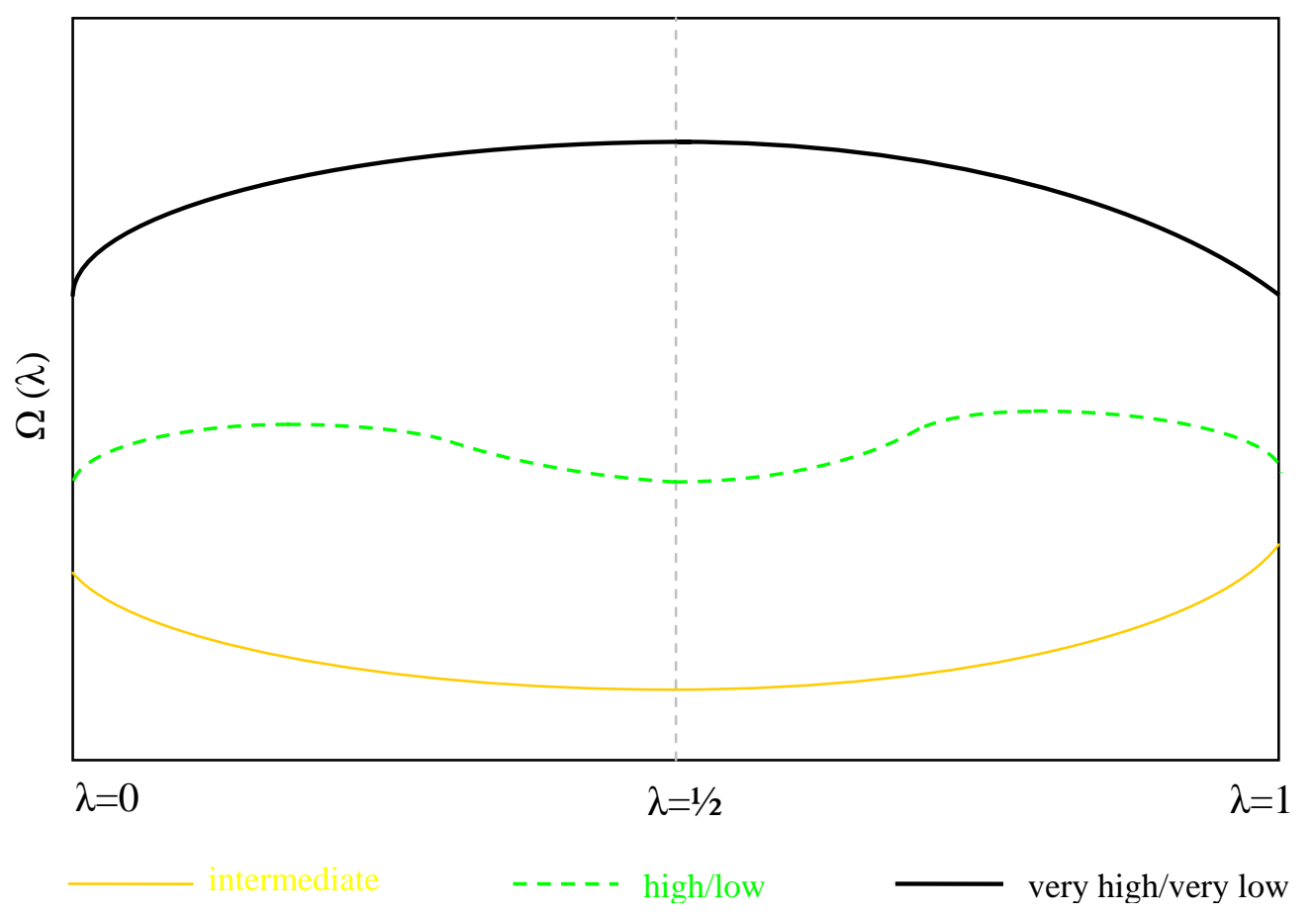

Figure 4: Market equilibrium and optimal spatial structure

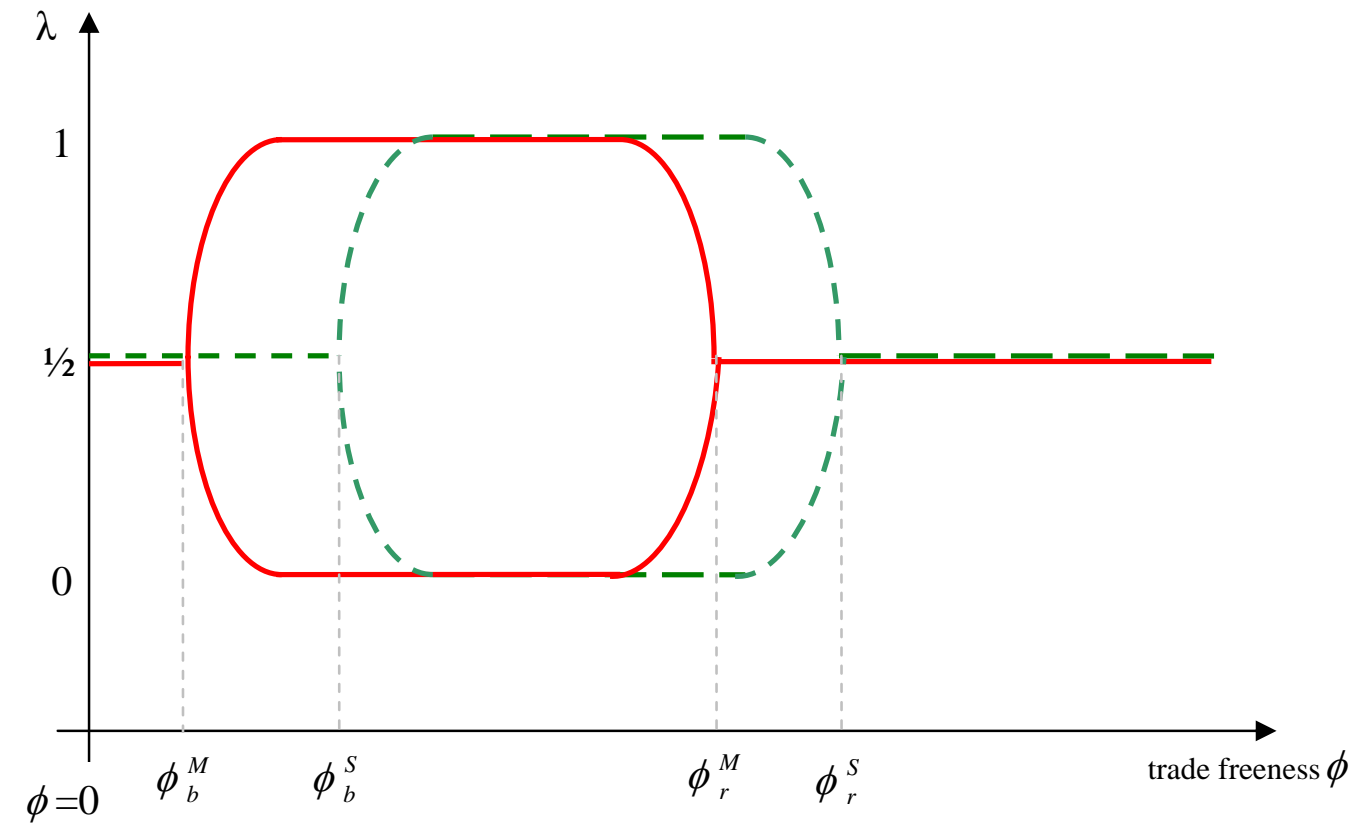

